\title{
Identification of Pancreatic Injury in Patients with Elevated Amylase or Lipase Level Using a Decision Tree Classifier: A Cross-Sectional Retrospective Analysis in a Level I Trauma Center
}

\author{
Cheng-Shyuan Rau ${ }^{1,+}$, Shao-Chun $\mathrm{Wu}^{2,+}$, Peng-Chen Chien ${ }^{3}$, Pao-Jen Kuo ${ }^{3}$, Yi-Chun Chen ${ }^{3}$, \\ Hsiao-Yun Hsieh ${ }^{3}$, Ching-Hua Hsieh ${ }^{3, *}$ (1) and Hang-Tsung Liu ${ }^{4, *}$ \\ 1 Department of Neurosurgery, Kaohsiung Chang Gung Memorial Hospital, Kaohsiung 83301, Taiwan; \\ ersh2127@cloud.cgmh.org.tw \\ 2 Department of Anesthesiology, Kaohsiung Chang Gung Memorial Hospital, Kaohsiung 83301, Taiwan; \\ shaochunwu@gmail.com \\ 3 Department of Plastic Surgery, Kaohsiung Chang Gung Memorial Hospital, Kaohsiung 83301, Taiwan; \\ venu_chien@hotmail.com (P.-C.C.); bow110470@gmail.com (P.-J.K.); libe320@yahoo.com.tw (Y.-C.C.); \\ sylvia19870714@hotmail.com (H.-Y.H.) \\ 4 Department of Trauma Surgery, Kaohsiung Chang Gung Memorial Hospital, Kaohsiung 83301, Taiwan \\ * Correspondence: m93chinghua@gmail.com (C.-H.H.); ht11688@yahoo.com.tw (H.-T.L.); \\ Tel.: +886-7-3454746 (C.-H.H.) \\ $\dagger$ These authors contributed equally to this work.
}

Received: 24 November 2017; Accepted: 4 February 2018; Published: 6 February 2018

\begin{abstract}
Background: In trauma patients, pancreatic injury is rare; however, if undiagnosed, it is associated with high morbidity and mortality rates. Few predictive models are available for the identification of pancreatic injury in trauma patients with elevated serum pancreatic enzymes. In this study, we aimed to construct a model for predicting pancreatic injury using a decision tree (DT) algorithm, along with data obtained from a population-based trauma registry in a Level I trauma center. Methods: A total of 991 patients with elevated serum levels of amylase ( $>137 \mathrm{U} / \mathrm{L}$ ) or lipase $(>51 \mathrm{U} / \mathrm{L}$ ), including 46 patients with pancreatic injury and 865 without pancreatic injury between January 2009 and December 2016, were allocated in a ratio of 7:3 to training $(n=642)$ or test $(n=269)$ sets. Using the data on patient and injury characteristics as well as laboratory data, the DT algorithm with Classification and Regression Tree (CART) analysis was performed based on the Gini impurity index, using the rpart function in the rpart package in R. Results: Among the trauma patients with elevated amylase or lipase levels, three groups of patients were identified as having a high risk of pancreatic injury, using the DT model. These included (1) $69 \%$ of the patients with lipase level $\geq 306 \mathrm{U} / \mathrm{L}$; (2) 79\% of the patients with lipase level between $154 \mathrm{U} / \mathrm{L}$ and $305 \mathrm{U} / \mathrm{L}$ and shock index (SI) $\geq 0.72$; and (3) $80 \%$ of the patients with lipase level $<154 \mathrm{U} / \mathrm{L}$ with abdomen injury, glucose level $<158 \mathrm{mg} / \mathrm{dL}$, amylase level $<90 \mathrm{U} / \mathrm{L}$, and neutrophil percentage $\geq 76 \%$; they had all sustained pancreatic injury. With all variables in the model, the DT achieved an accuracy of $97.9 \%$ (sensitivity of $91.4 \%$ and specificity of $98.3 \%$ ) for the training set. In the test set, the DT achieved an accuracy of $93.3 \%$, sensitivity of $72.7 \%$, and specificity of $94.2 \%$. Conclusions: We established a DT model using lipase, SI, and additional conditions (injury to the abdomen, glucose level $<158 \mathrm{mg} / \mathrm{dL}$, amylase level $<90 \mathrm{U} / \mathrm{L}$, and neutrophils $\geq 76 \%$ ) as important nodes to predict three groups of patients with a high risk of pancreatic injury. The proposed decision-making algorithm may help in identifying pancreatic injury among trauma patients with elevated serum amylase or lipase levels.
\end{abstract}


Keywords: decision tree; pancreatic injury; amylase; lipase; abdominal injury; shock; traumatic brain injury; mandible fracture; maxilla fracture

\section{Background}

The overall incidence of pancreatic injury is relatively uncommon and has been estimated to be $1-2 \%$ of all patients with abdominal injuries. Nontheless, when it does occur, there was overall mortality rate ranged from $5 \%$ to $13 \%$ and a pancreatic morbidity of $11 \%$ [1-4]. Furthermore, trauma to the pancreatic duct can induce autodigestion of the adjacent tissue by secreted exocrine enzymes, leading to an associated risk of erosion of adjacent vascular and visceral structures $[1,5]$. The clinical presentation of pancreatic injury is often subtle because of the organ's retroperitoneal location. Diagnosis that is delayed more than $24 \mathrm{~h}$ has been cited as the leading cause of increased morbidity, particularly in association with other blunt abdominal trauma [6,7]. Therefore, pancreatic injury should be diagnosed as early as possible to prevent serious complications and decrease the mortality that can result from delayed diagnosis.

Pancreatic enzymes may be released into the circulation as a result of damage to tissues containing high enzyme levels or by release from the gastrointestinal tract [8-10]. Obstruction of the bile or pancreatic duct and bowel can further lead to direct diffusion of pancreatic enzymes from the intestinal lumen into the bloodstream [11]. In consequence, serum amylase and lipase levels are often used as a diagnostic screening tool to detect pancreatic injury. However, published reports on serum levels of amylase and lipase in patients with abdominal trauma have shown mixed results. Some studies have clearly shown the importance of serum amylase and lipase levels in diagnosing pancreatic injury $[6,7,12]$ but others have demonstrated that initial amylase and lipase measurements are not useful screening tools for detecting pancreatic injury [13-16].

The abovementioned disagreement may be attributed to the fact that, besides the pancreas, many different organs such as the tongue, esophagus, stomach, duodenum, small bowel, and liver contain amylase and lipase [17]. Amylase in different isoforms may be released from salivary glands following trauma upon this region [18]. Moreover, in a variety of shock states, clinical studies have demonstrated evidence of ischemic pancreatic inflammation with elevated levels of pancreatic enzymes $[19,20]$. In a study of 164 consecutive patients who presented to the emergency department (ED) with a history of blunt abdominal trauma and who had serum pancreatic enzyme assessment, $66 \%$ of patients had associated intra-abdominal injury, with $43 \%$ involving the duodenum, $15 \%$ with associated head injury, and 51\% with associated extremity injury [12]. Hence, increased serum levels of amylase and lipase are not always predictive of pancreatic injury and may also reflect nonpancreatic or extrapancreatic production. An increase in serum levels of these enzymes can be caused by a broad range of conditions in patients with trauma, such as those with blunt abdominal injury [21], intracranial bleeding [22,23], critical illness in an intensive care unit $[24,25]$, patients recovering from shock $[20,26]$, and those undergoing maxillofacial surgery [18].

In this study, we adopted the decision tree (DT) method to explore the variables that could be used to identify individuals at risk for pancreatic injury among trauma patients with elevated amylase or lipase levels. DT is a machine learning model, which is composed of decision rules based on optimal feature cutoff values that recursively split independent variables into different groups and predict an outcome in a hierarchical manner [27-29]. To identify high-risk patients with pancreatic injury in clinical decision-making from among those with elevated serum levels of amylase or lipase, we aimed to construct a model to predict pancreatic injury using the DT algorithm and data obtained from a population-based trauma registry in a level I trauma center. 


\section{Methods}

\subsection{Study Population}

After approval (reference number 201701369B0) was obtained from the institutional review board of the Kaohsiung Chang Gung Memorial Hospital, a level I regional trauma center in southern Taiwan [30,31], we searched the database of the Trauma Registry System from 1 January 2009 to 31 December 2016 and reviewed medical charts for diagnostic injury codes 863.81-863.84 and 863.91-863.94 (pancreatic injury), according to the International Classification of Diseases, 9th Revision, Clinical Modification (ICD-9-CM). All patients who presented with elevated serum levels of amylase $(>137 \mathrm{U} / \mathrm{L}$ ) or lipase ( $>51 \mathrm{U} / \mathrm{L}$ ) were included in the study. Of the 971 patients identified as having elevated amylase or lipase levels, 60 were excluded due to incomplete registry data or lack of laboratory blood testing data. Finally, 911 patients were included in this study. Among these, 46 patients had sustained a pancreatic injury, which had been identified either by abdominal computed tomography examination or during a laparotomy; the other 865 patients did not have pancreatic injury.

The following data were retrieved: sex; age; co-morbidities such as diabetes mellitus (DM), hypertension (HTN), coronary artery disease (CAD), congestive heart failure, cerebral vascular accident, and end-stage renal disease; associated injuries or illness that may induce elevated amylase or lipase, including traumatic brain injury (TBI), mandible fracture, maxillary fracture, perforated peptic ulcer (PPU), ileus, torsion of ovarian cyst, mesenteric ischemia, intestinal strangulation, and mumps; vital signs, including temperature, systolic blood pressure (SBP), heart rate (HR), respiratory rate; Injury Severity Score (ISS); Glasgow coma scale (GCS) score; Abbreviated Injury Scale (AIS) score for different regions of the body; white blood cell (WBC) and red blood cell counts, percentage of neutrophils in WBCs; levels of hemoglobin, hematocrit, platelets, blood urine nitrogen (BUN), creatinine (Cr), alanine aminotransferase, aspartate aminotransferase, total bilirubin, sodium, potassium, amylase, lipase, and glucose; international normalized ratio (INR); and shock index (SI), calculated in the ED, as HR divided by SBP.

\subsection{Decision Tree Classifier}

The 911 enrolled patients were divided in a ratio of 7:3 into a training set $(n=642)$ and a test set $(n=269)$. The training set was used for predictor discovery under supervised classification and to generate a plausible model. The test set was used to assess the performance of the model generated from the training set. Classification and Regression Trees (CART) analysis [32,33] using the rpart function in the rpart package in R, based on the Gini impurity index, was used to establish the DT classification model. CART analysis was used to search for the split on each variable to partition the data into two groups: one group of mostly " $1 \mathrm{~s}$ " (people who had sustained pancreatic injury) and another group of mostly "0s" (people who did not have pancreatic injury). The CART model partitioned the data and assigned a predicted class to each subgroup. With repetition of the same process on each predictor in the model, CART identified the best overall split by iteratively testing all possible splits and creating a specified number of nodes, until the specified stopping criteria were reached or a further reduction in node impurity became impossible [34-36]. In this study, the method of "cost-complexity" pruning was used to generate a sequence of simpler trees. The complexity parameter $(\alpha)$, a measure of how much additional accuracy a split must add to the entire tree to warrant additional complexity, was set at 0.001 .

\subsection{Multivariate Logistic Regression}

For comparison, the multivariate logistic regression (LR) classifier using glm function of the stats package in $\mathrm{R}$ was performed. A univariate $\mathrm{LR}$ analysis was initially performed to identify significant predictors of pancreatic injury. All significant variables derived from univariate analysis were entered into the multiple LR using stepwise elimination to identify independent risk factors for pancreatic 
injury. A prediction model was developed using the calculated probability value assigned to final variables based on its regression coefficient.

\subsection{Performance of the Decision Tree Classifier}

Stratified 10-fold cross-validation was used in the test set to evaluate the predictive power of the models. Briefly, patients were randomly divided into 10 folds; the number of patients with an event was approximately equal in all folds. The model was developed using nine folds and validation on the tenth. The accuracy, sensitivity, and specificity of the DT model were calculated.

\subsection{Statistical Analysis}

Statistical analyses were performed using IBM SPSS Statistics for Windows, version 20.0 (IBM Corp., Armonk, NY, USA) and R 3.3.3. (R Foundation for Statistical Computing, Vienna, Austria). The primary outcome of the study was in-hospital mortality. Two-sided Fisher's exact or Pearson chi-square tests were used to compare categorical data, with odds ratios (ORs) and 95\% confidence intervals (CIs). The normality of continuous data was examined using the Kolmogorov-Smirnov test. Mann-Whitney $U$-tests were used to analyze non-normally distributed data, which are presented as median with interquartile range (IQR, Q1-Q3). Measures of model performance regarding the area under the curve (AUC) of the receiver operator characteristic curves (ROCs) was performed using the roc \& roc.test function in the pROC package in R. $p$-Values $<0.05$ were defined as statistically significant.

\section{Results}

\subsection{Characteristics and Outcomes of Patients with Elevated Amylase or Lipase Levels}

As shown in Table 1, no significant differences in sex were observed between patients with and without pancreatic injury. Compared with patients who did not have pancreatic injury, those with pancreatic injury had significantly lower rates of pre-existing HTN and DM as well as associated TBI and maxillary fracture owing to trauma accident. No significant difference in the rates of associated injury or illness including maxillary fracture, PPU, torsion of ovarian cyst, and ileus were found between the two patient groups. In addition, patients with pancreatic injury had significantly higher rates of elevated AIS scores in abdominal regions, but lower AIS scores in areas of the head, face and extremities than did patients without pancreatic injury. All the continuous data did not pass the normality examination by Kolmogorov-Smirnov test. Patients with pancreatic injury were significantly older, had significantly higher GCS, neutrophils (\%), amylase and lipase levels, and INR level but lower SBP, ISS, glucose, BUN, and Cr level than patients without pancreatic injury (Table 2). Among the 911 patients, there were 327 who had sustained TBI, 65 with mandible fracture, 119 with maxilla fracture, 4 with PPU, 3 with ileus, and one patient with torsion of ovarian cyst (Table 3). Among these patients, 176 and 210 of the 327 patients with TBI had a high level of amylase and lipase, respectively; 43 and 37 of the 65 patients with mandibular fracture presented with a high level of amylase and lipase, respectively; and 75 and 70 of the 119 patients with maxillary fracture had a high level of amylase and lipase, respectively. Notably, among patients with TBI, mean levels of amylase and lipase were $172 \mathrm{U} / \mathrm{L}$ and $71 \mathrm{U} / \mathrm{L}$, respectively. Though, maximal levels of amylase and lipase in these patients reached $1960 \mathrm{U} / \mathrm{L}$ and $767 \mathrm{U} / \mathrm{L}$, respectively. Further, in patients with mandible or maxilla fracture, the mean amylase level was extremely high, up to around $2000 \mathrm{U} / \mathrm{L}$; After all, the mean lipase level was around $76 \mathrm{U} / \mathrm{L}$, albeit in some patients the lipase level reached about $542 \mathrm{U} / \mathrm{L}$. In this study, no patients had mesenteric ischemia, intestinal strangulation, or mumps. 
Table 1. Comparison of categorical variables of patient and injury characteristics, used to establish the decision tree model, between patients with and without pancreatic injury.

\begin{tabular}{|c|c|c|c|c|c|}
\hline \multirow{2}{*}{ Variables } & & \multirow{2}{*}{ Total $(n=911)$} & \multicolumn{2}{|c|}{ Pancreatic Injury } & \multirow{2}{*}{$p$-Value } \\
\hline & & & No $(n=865)$ & Yes $(n=46)$ & \\
\hline \multirow[b]{2}{*}{ Sex } & Female & $325(35.7 \%)$ & $303(35 \%)$ & $22(48 \%)$ & \multirow[b]{2}{*}{0.084} \\
\hline & Male & $586(64.3 \%)$ & $562(65 \%)$ & $24(52 \%)$ & \\
\hline \multirow{2}{*}{ CVA } & No & $896(98.4 \%)$ & $850(98.3 \%)$ & $46(100 \%)$ & \multirow{2}{*}{$>0.999$} \\
\hline & Yes & $15(1.6 \%)$ & $15(1.7 \%)$ & $0(0 \%)$ & \\
\hline \multirow{2}{*}{ CAD } & No & $885(97.1 \%)$ & $839(96.9 \%)$ & $46(100 \%)$ & \multirow{2}{*}{0.637} \\
\hline & Yes & $26(2.9 \%)$ & $26(3.1 \%)$ & $0(0 \%)$ & \\
\hline \multirow{2}{*}{ HTN } & No & $729(80.0 \%)$ & $685(79.2 \%)$ & $44(47.8 \%)$ & \multirow{2}{*}{0.004} \\
\hline & Yes & $182(20 \%)$ & $180(20.8 \%)$ & $2(2.2 \%)$ & \\
\hline \multirow{2}{*}{$\mathrm{CHF}$} & No & $905(99.3 \%)$ & $859(99.3 \%)$ & $46(100 \%)$ & \multirow{2}{*}{$>0.999$} \\
\hline & Yes & $6(0.7 \%)$ & $6(0.7 \%)$ & $0(0 \%)$ & \\
\hline FSRD & No & $880(96.6 \%)$ & $834(96.4 \%)$ & $46(100 \%)$ & \\
\hline ESTE & Yes & $31(3.4 \%)$ & $31(3.6 \%)$ & $0(0 \%)$ & 0.398 \\
\hline & No & $793(87 \%)$ & $747(86.4 \%)$ & $46(100 \%)$ & \\
\hline DM & Yes & $118(13 \%)$ & $118(13.6 \%)$ & $0(0 \%)$ & 0.003 \\
\hline & No & $584(64.1 \%)$ & $544(62.9 \%)$ & $40(87 \%)$ & \\
\hline IDI & Yes & $327(35.9 \%)$ & $321(37.1 \%)$ & $6(13 \%)$ & 0.001 \\
\hline & No & $846(92.9 \%)$ & $800(92.5 \%)$ & $46(100 \%)$ & \\
\hline Mandible fracture & Yes & $65(7.1 \%)$ & $65(7.5 \%)$ & $0(0 \%)$ & 0.069 \\
\hline & No & $792(86.9 \%)$ & $746(86.2 \%)$ & $46(100 \%)$ & \\
\hline Maxilla fracture & Yes & $119(13.1 \%)$ & $119(13.8 \%)$ & $0(0 \%)$ & 0.003 \\
\hline & No & $907(99.6 \%)$ & $861(99.5 \%)$ & $46(100 \%)$ & \\
\hline PPU & Yes & $4(0.4 \%)$ & $4(0.5 \%)$ & $0(0 \%)$ & $>0.999$ \\
\hline & No & 908 (99.7\%) & $862(99.7 \%)$ & $46(100 \%)$ & \\
\hline lleus & Yes & $3(0.3 \%)$ & $3(0.3 \%)$ & $0(0 \%)$ & $>0.999$ \\
\hline & No & $910(99.9 \%)$ & $864(99.9 \%)$ & $46(100 \%)$ & \\
\hline Iorsion of ovarian cyst & Yes & $1(0.1 \%)$ & $1(0.1 \%)$ & $0(0 \%)$ & $>0.999$ \\
\hline & 0 & $382(41.9 \%)$ & $346(40 \%)$ & $36(78.3 \%)$ & \\
\hline & 1 & $114(12.5 \%)$ & $110(12.7 \%)$ & $4(8.7 \%)$ & \\
\hline & 2 & $49(5.4 \%)$ & $47(5.4 \%)$ & $2(4.3 \%)$ & \\
\hline AIS (Head) & 3 & $159(17.5 \%)$ & $155(17.9 \%)$ & $4(8.7 \%)$ & $<0.001$ \\
\hline & 4 & $140(15.4 \%)$ & $140(16.2 \%)$ & $0(0 \%)$ & \\
\hline & 5 & $60(6.6 \%)$ & $60(6.9 \%)$ & $0(0 \%)$ & \\
\hline & 6 & $7(0.8 \%)$ & $7(0.8 \%)$ & $0(0 \%)$ & \\
\hline & 0 & $655(71.9 \%)$ & $611(70.6 \%)$ & $44(95.7 \%)$ & \\
\hline & 1 & $62(6.8 \%)$ & $60(6.9 \%)$ & $2(4.3 \%)$ & \\
\hline AIs (Face) & 2 & $182(20 \%)$ & $182(21 \%)$ & $0(0 \%)$ & 0.002 \\
\hline & 3 & $12(1.3 \%)$ & $12(1.4 \%)$ & $0(0 \%)$ & \\
\hline & 0 & $555(60.9 \%)$ & $515(59.5 \%)$ & $40(87 \%)$ & \\
\hline & 1 & $37(4.1 \%)$ & $35(4 \%)$ & $2(4.3 \%)$ & \\
\hline & 2 & $71(7.8 \%)$ & $71(8.2 \%)$ & $0(0 \%)$ & \\
\hline AIS (Thorax) & 3 & $146(16 \%)$ & $144(16.6 \%)$ & $2(4.3 \%)$ & 0.009 \\
\hline & 4 & $93(10.2 \%)$ & $91(10.5 \%)$ & $2(4.3 \%)$ & \\
\hline & 5 & $9(1 \%)$ & $9(1 \%)$ & $0(0 \%)$ & \\
\hline & 0 & $547(60 \%)$ & $545(63 \%)$ & $2(4.3 \%)$ & \\
\hline & 1 & $23(2.5 \%)$ & $23(2.7 \%)$ & $0(0 \%)$ & \\
\hline AIS (Abdomen) & 2 & $165(18.1 \%)$ & $149(17.2 \%)$ & $16(34.8 \%)$ & \\
\hline AIs (Abaomen) & 3 & $101(11.1 \%)$ & $89(10.3 \%)$ & $12(26.1 \%)$ & $<0.001$ \\
\hline & 4 & $60(6.6 \%)$ & $46(5.3 \%)$ & $14(30.4 \%)$ & \\
\hline & 5 & $15(1.6 \%)$ & $13(1.5 \%)$ & $2(4.3 \%)$ & \\
\hline & 0 & $413(45.3 \%)$ & $381(44 \%)$ & $32(69.6 \%)$ & \\
\hline & 1 & $55(6 \%)$ & $53(6.1 \%)$ & $2(4.3 \%)$ & \\
\hline & 2 & $235(25.8 \%)$ & $229(26.5 \%)$ & $6(13 \%)$ & \\
\hline AIs (Extremity) & 3 & $190(20.9 \%)$ & $186(21.5 \%)$ & $4(8.7 \%)$ & 0.008 \\
\hline & 4 & $14(1.5 \%)$ & $12(1.4 \%)$ & $2(4.3 \%)$ & \\
\hline & 5 & $4(0.4 \%)$ & $4(0.5 \%)$ & $0(0 \%)$ & \\
\hline & 0 & $770(84.5 \%)$ & $732(84.6 \%)$ & $38(82.6 \%)$ & \\
\hline & 1 & $126(13.8 \%)$ & $118(13.6 \%)$ & $8(17.4 \%)$ & \\
\hline & 2 & $6(0.7 \%)$ & $6(0.7 \%)$ & $0(0 \%)$ & \\
\hline AIS (External) & 3 & $4(0.4 \%)$ & $4(0.5 \%)$ & $0(0 \%)$ & 0.974 \\
\hline & 4 & $1(0.1 \%)$ & $1(0.1 \%)$ & $0(0 \%)$ & \\
\hline & 5 & $1(0.1 \%)$ & $1(0.1 \%)$ & $0(0 \%)$ & \\
\hline & 6 & $3(0.3 \%)$ & $3(0.3 \%)$ & $0(0 \%)$ & \\
\hline
\end{tabular}

AIS $=$ abbreviated injury scale; $\mathrm{CAD}=$ coronary artery disease $; \mathrm{CHF}=$ congestive heart failure; $\mathrm{CVA}=$ cerebral vascular accident; $\mathrm{DM}=$ diabetes mellitus; $\mathrm{ESRD}$ = end-stage renal disease; HTN = hypertension; $\mathrm{PPU}$ = perforated peptic ulcer; $\mathrm{TBI}=$ traumatic brain injury. 
Table 2. Comparison of continuous variables of patient and injury characteristics, used in the decision tree model, between patients with and without pancreatic injury.

\begin{tabular}{|c|c|c|c|c|}
\hline \multirow[b]{2}{*}{ Variables } & \multirow{2}{*}{$\begin{array}{l}\text { Total }(n=911) \\
\text { Median (IQR) }\end{array}$} & \multicolumn{2}{|c|}{ Pancreatic Injury } & \multirow[b]{2}{*}{$p$-Value } \\
\hline & & $\begin{array}{c}\text { No }(n=865) \\
\text { Median (IQR) }\end{array}$ & $\begin{array}{c}\text { Yes }(n=46) \\
\text { Median (IQR) }\end{array}$ & \\
\hline Age (years) & $45(26-61)$ & $46(26-61)$ & $39(18-59)$ & 0.039 \\
\hline $\mathrm{SBP}(\mathrm{mmHg})$ & $133(108-155)$ & $133(108-156)$ & $121(105-144)$ & 0.032 \\
\hline RR (times/min) & $20(18-20)$ & $20(18-20)$ & $20(18-20)$ & 0.714 \\
\hline Temperature $\left({ }^{\circ} \mathrm{C}\right)$ & $36.4(36-36.9)$ & $36.4(36-36.9)$ & $36.4(36.1-36.8)$ & 0.908 \\
\hline GCS & $15(9-15)$ & $15(9-15)$ & $15(14-15)$ & 0.001 \\
\hline ISS & $16(9-24)$ & $16(9-24)$ & $10(8-18)$ & 0.022 \\
\hline $\operatorname{RBC}\left(10^{6} / \mu \mathrm{L}\right)$ & $4.3(3.8-4.7)$ & $4.3(3.8-4.7)$ & $4.0(3.6-4.6)$ & 0.115 \\
\hline $\mathrm{WBC}\left(10^{3} / \mu \mathrm{L}\right)$ & $13.5(9.5-18.8)$ & $13.5(9.5-19)$ & $12.6(9-14.8)$ & 0.092 \\
\hline Neutrophil (\%) & $77.1(65-85.8)$ & $76.2(64.4-85.5)$ & $85.2(78.8-89)$ & $<0.001$ \\
\hline $\mathrm{Hb}(\mathrm{g} / \mathrm{dL})$ & $12.7(11.2-14.3)$ & $12.7(11.2-14.3)$ & $12.3(10.8-14.5)$ & 0.300 \\
\hline Hct $(\%)$ & $37.9(33.6-41.9)$ & $38.0(33.7-42)$ & $37.2(32.7-41.2)$ & 0.318 \\
\hline Platelets $\left(10^{3} / \mu \mathrm{L}\right)$ & $206(161-251)$ & $206(161-253)$ & $202(164-230)$ & 0.734 \\
\hline Glucose $(\mathrm{mg} / \mathrm{dL})$ & 177 (136-179) & $177(136-179)$ & $150(149-168)$ & 0.023 \\
\hline $\mathrm{Na}(\mathrm{mEq} / \mathrm{L})$ & $139(137-141)$ & 139 (137-141) & $140(137-141)$ & 0.213 \\
\hline $\mathrm{K}(\mathrm{mEq} / \mathrm{L})$ & $3.6(3.2-4.0)$ & $3.6(3.2-4.0)$ & $3.7(3.5-3.9)$ & 0.121 \\
\hline BUN (mg/dL) & $14(10-18)$ & $14(10-18)$ & $12.3(8-14)$ & 0.007 \\
\hline $\mathrm{Cr}(\mathrm{mg} / \mathrm{dL})$ & $0.9(0.8-1.2)$ & $1.0(0.8-1.2)$ & $0.8(0.7-0.9)$ & $<0.001$ \\
\hline AST $(\mathrm{U} / \mathrm{L})$ & $86(41-184)$ & $83(41-189.5)$ & $100(61-179)$ & 0.179 \\
\hline $\operatorname{ALT}(\mathrm{U} / \mathrm{L})$ & $49(26-120)$ & $49(26-121)$ & $65(40-96)$ & 0.190 \\
\hline Total bilirubin $(\mathrm{mg} / \mathrm{dL})$ & $0.9(0.7-0.9)$ & $0.9(0.6-0.9)$ & $0.9(0.8-1.0)$ & 0.090 \\
\hline Amylase (U/L) & $136(84-183)$ & $136(84-179)$ & $148(87-554)$ & 0.005 \\
\hline Lipase (U/L) & $61(45-89)$ & $60(43-84)$ & $176(97-375)$ & $<0.001$ \\
\hline INR & $1.1(1.0-1.2)$ & $1.1(1.0-1.1)$ & $1.1(1.0-1.2)$ & 0.044 \\
\hline SI & $0.7(0.6-0.9)$ & $0.7(0.6-1.0)$ & $0.7(0.6-0.9)$ & 0.589 \\
\hline
\end{tabular}

ALT = alanine aminotransferase; AST $=$ Aspartate transaminase; $\mathrm{BUN}=$ blood urea nitrogen; $\mathrm{Cr}=$ creatinine; $\mathrm{GCS}=$ Glasgow coma scale; $\mathrm{Hb}=$ hemoglobin; $\mathrm{Hct}=$ hematocrit; INR = international normalized ratio; $\mathrm{K}=$ potassium; $\mathrm{Na}=$ sodium; $\mathrm{ISS}=$ injury severity score; $\mathrm{RBC}=$ red blood cells; $\mathrm{RR}=$ respiratory rate; $\mathrm{SBP}$ = systolic blood pressure; $\mathrm{SI}=$ shock index; $\mathrm{WBC}=$ white blood cells. These continuous data was expressed with median and interquartile range.

Table 3. Serum amylase and lipase levels of patients with an associated injury or illness.

\begin{tabular}{|c|c|c|c|c|c|c|c|c|c|}
\hline \multirow[b]{2}{*}{ Variables } & \multirow[t]{2}{*}{ Total $(n)$} & \multicolumn{4}{|c|}{ Amylase } & \multicolumn{4}{|c|}{ Lipase } \\
\hline & & $\begin{array}{c}\text { Median } \\
\text { (IQR) }\end{array}$ & Max & Min & $\underset{(n)}{\geq 138 \mathrm{U} / \mathrm{L}}$ & $\begin{array}{c}\text { Median } \\
\text { (IQR) }\end{array}$ & Max & Min & $\underset{\mathrm{U} / \mathrm{L}(n)}{\geq 52}$ \\
\hline Traumatic brain injury & 327 & $142(87-182)$ & 1960 & 12 & 176 & $56(38-73)$ & 767 & 12 & 210 \\
\hline Mandible fracture & 65 & $160(107-239)$ & 843 & 47 & 43 & $55(28-78)$ & 542 & 2.1 & 37 \\
\hline Maxilla fracture & 119 & 155 (105-227) & 956 & 40 & 75 & $54(33-75)$ & 542 & 15 & 70 \\
\hline Perforated peptic ulcer & 4 & $202(130-254)$ & 267 & 55 & 3 & 75 (49-93) & 93 & 27 & 3 \\
\hline Torsion of ovarian cyst & 1 & - & 84 & 84 & 0 & - & 72 & 72 & 1 \\
\hline Ileus & 3 & $103(89-118)$ & 132 & 74 & 0 & $89(81-132)$ & 174 & 73 & 3 \\
\hline
\end{tabular}

\subsection{Classification by Decision Tree Algorithm}

As shown in Figure 1, the lipase level was identified in the DT model as the variable of the initial split, with an optimal cutoff value of $<306 \mathrm{U} / \mathrm{L}$. Among patients with lipase level $\geq 306 \mathrm{U} / \mathrm{L}, 69 \%$ had pancreatic injury and 31\% did not. Among patients with lipase level between $154 \mathrm{U} / \mathrm{L}$ and $305 \mathrm{U} / \mathrm{L}$, SI was identified as the variable of the second split, with an optimal cutoff value $\geq 0.72$. For the node, only $3 \%$ of patients with SI $\geq 0.72$ had sustained pancreatic injury. In contrast, $79 \%$ of patients with SI $<0.72$ had pancreatic injury. Among patients with lipase level $<154 \mathrm{U} / \mathrm{L}$, the presence of abdominal injury (AIS abdomen $<1$ ), glucose level $\geq 158 \mathrm{mg} / \mathrm{dL}$, amylase $\geq 90 \mathrm{U} / \mathrm{L}$, and neutrophils $<76 \%$ served as additional predictors for the determination of associated pancreatic injury in patients. This indicated that among patients with a lipase level $<154 \mathrm{U} / \mathrm{L}, 80 \%$ of those with abdomen injury, glucose level $<158 \mathrm{mg} / \mathrm{dL}$, amylase level $<90 \mathrm{U} / \mathrm{L}$, and neutrophil percentage $\geq 76 \%$ had sustained pancreatic injury. Among patients with a lipase level $<154 \mathrm{U} / \mathrm{L}$, only $1 \%$ of those with abdomen injury and glucose level $\geq 158 \mathrm{mg} / \mathrm{dL}$ had sustained pancreatic injury. According to classification by the DT, three groups of trauma patients with a high risk of pancreatic injury were identified (Figure 1). With all 
variables in the model, the DT achieved an accuracy of $97.9 \%$ (sensitivity of $91.4 \%$ and specificity of $98.3 \%$ ) for the training set. In the test set, the DT achieved an accuracy of $93.3 \%$, sensitivity of $72.7 \%$, and specificity of $94.2 \%$. The DT model had an AUC of 0.901 of all samples and AUC of 0.812 of test set in predicting a pancreatic injury (Figure 2).

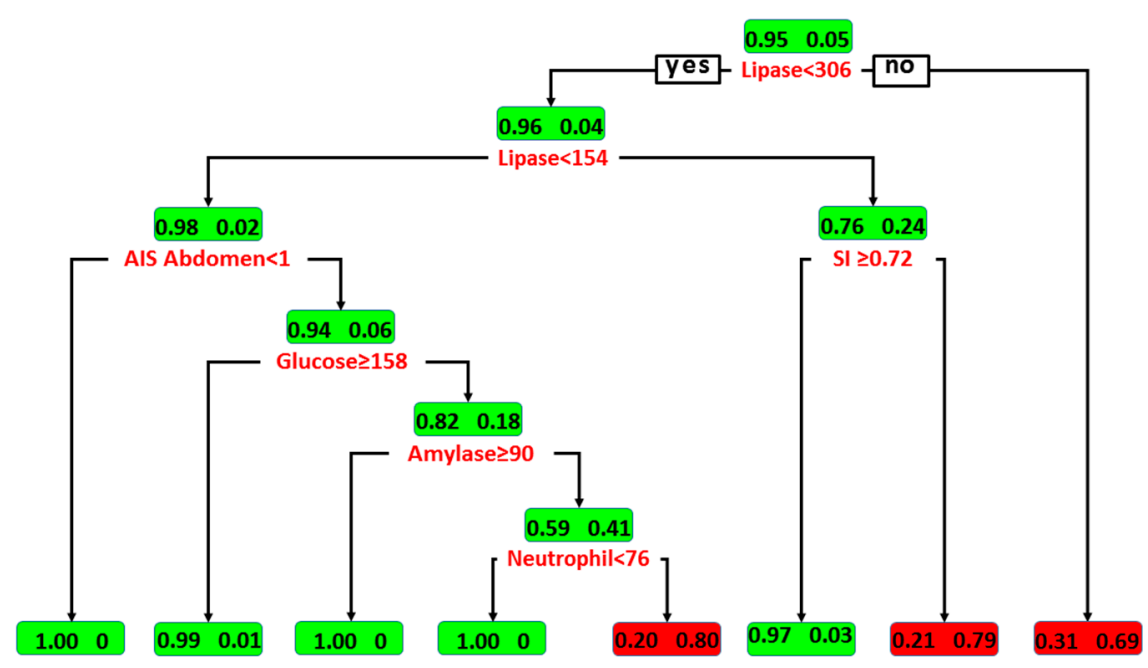

Figure 1. Illustration of DT model for predicting pancreatic injury in patients with elevated serum amylase or lipase levels. Boxes denote the percentage of patients with discriminating variables from CART analysis. Patients with and without pancreatic injury are indicated by the fractional number inside the right and left sides of the boxes, respectively.
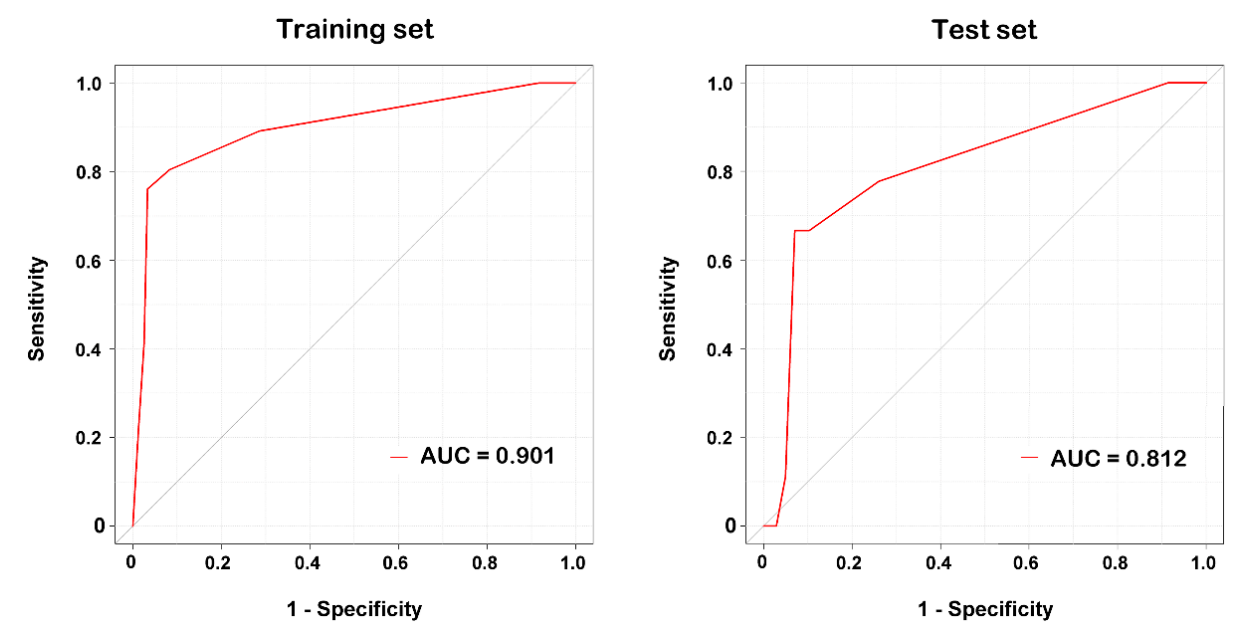

Figure 2. Illustration of ROC curves for the DT model in the training and test set.

\subsection{Classification by Multivariate LR}

The final multivariate regression models revealed that the pancreatic injury were associated with 12 independent risk factors, which included WBC, Cr, AST, ALT, Na, lipase, AIS of face, AIS of thorax, AIS of abdomen, AIS of extremity, DM (Table 4). With all variables in the model, the logistic model achieved an accuracy of $96.9 \%$ (sensitivity of $56.8 \%$ and specificity of $99.3 \%$ ) for the training set. In the test set, the logistic model achieved an accuracy of $98.1 \%$, sensitivity of $77.7 \%$, and specificity of $98.8 \%$. 
Table 4. Independent risk factors for pancreatic injury in multivariate logistic regression.

\begin{tabular}{cccc}
\hline Independent Variables & Coefficient & Independent Variables & Coefficient \\
\hline WBC & 0.6911 & lipase & -0.2176 \\
neutrophil & 0.1522 & AIS of face & -0.3066 \\
Cr & 0.1061 & AIS of thorax & -0.5152 \\
AST & 0.0094 & AIS of abdomen & -1.848 \\
ALT & 0.0073 & AIS of extremity & -2.1096 \\
Na & -0.0164 & DM & -19.4426 \\
\hline Intercept & -47.4648 & & \\
\hline
\end{tabular}

\section{Discussion}

In this DT model, the lipase level was the first node in predicting pancreatic injury among patients with elevated pancreatic enzymes. According to well-accepted consensus, serum lipase level is the most important variable related to pancreatic injury. Elevated serum lipase level served as a more specific marker than amylase for pancreatic injury [12]. In contrast, elevated levels of pancreatic enzymes among critically injured patients in the absence of pancreatic injury are generally owing to craniofacial injuries [23,37], such that the reliability of serum amylase levels to predict pancreatic injury is questionable [23]. Furthermore, amylase level is significantly associated with the time of measurement, particularly among patients in whom amylase was measured $2 \mathrm{~h}$ or less post-injury [38]. However, such an association is not significant for lipase measurements [38]. The risk of patients having a pancreatic injury can be determined according to the lipase level as (1) $\geq 306 \mathrm{U} / \mathrm{L}$; (2) between $154 \mathrm{U} / \mathrm{L}$ and $305 \mathrm{U} / \mathrm{L}$; or (3) <154 U/L. Among trauma patients with elevated amylase or lipase levels, we identified three groups of patients as having a high risk of pancreatic injury using the DT model. These groups were as follows: (1) $69 \%$ of patients with lipase level $\geq 306 \mathrm{U} / \mathrm{L}$ had sustained pancreatic injury; (2) 79\% of patients with lipase level between $154 \mathrm{U} / \mathrm{L}$ and $305 \mathrm{U} / \mathrm{L}$ and SI $\geq 0.72$ had sustained pancreatic injury; and (3) $80 \%$ of patients with lipase level $<154 \mathrm{U} / \mathrm{L}$ and who had sustained abdomen injury, glucose level $<158 \mathrm{mg} / \mathrm{dL}$, amylase level $<90 \mathrm{U} / \mathrm{L}$, and neutrophils $\geq 76 \%$ had pancreatic injury.

In this study, the maximum levels of lipase reached $767 \mathrm{U} / \mathrm{L}$ and $542 \mathrm{U} / \mathrm{L}$ in patients with TBI as well as injury to the mandible and maxilla, respectively. Thus, determination of pancreatic injury made by relying solely on the lipase level may result in a false positive diagnosis. For example, $31 \%$ of patients with lipase level $\geq 306 \mathrm{U} / \mathrm{L}$ in this study did not have pancreatic injury. The existence of TBI or fracture of the mandible or maxilla could explain a high serum level of lipase, as no patients had concurrent mandibular or maxillary fracture with pancreatic injury in this study; however, using trauma to the craniofacial area to exclude possible pancreatic injury among patients with high lipase levels may not be justified, particularly considering the possible occurrence of injury to the abdomen and craniofacial area; such patients may have levels of consciousness that are insufficiently alert to describe their abdominal injury.

The second important node in the prediction of pancreatic injury in this DT model was the SI. In this study, among patients with lipase level between $154 \mathrm{U} / \mathrm{L}$ and $305 \mathrm{U} / \mathrm{L}$, an SI $\geq 0.72$ determined pancreatic injury in $79 \%$ of patients. In contrast, only $3 \%$ of patients with $\mathrm{SI} \geq 0.72$ had a pancreatic injury. Histological and clinical evidence have demonstrated ischemic pancreatic inflammation in a variety of shock states [19]. Patients with an elevated level of pancreatic enzymes are at greater risk of presenting with shock [20]. The SI, which is the ratio of HR to SBP, has been used to identify hypovolemic shock in patients with trauma since 1967 [39]. SI is an easily obtained indicator of hemodynamic instability [40-42] and a clinical indicator of hypovolemic shock upon arrival to the ED [43]. In a study among healthy participants with blood loss of $450 \mathrm{ml}$, the SI was substantially increased whereas the HR and SBP remained within the normal ranges [44]. Classification of patients by an SI > 0.7 can preferentially select patients with adverse short-term outcomes from among those with upper gastrointestinal bleeding [45]. With SI above 0.9 , the risk for trauma patients requiring 
massive transfusion rises substantially [46]. Takahashi et al. reported that $80 \%$ of patients with traumatic shock but without pancreatic injury had elevated serum amylase levels and $94 \%$ of them had elevated amylase owing to secretion from salivary glands [37]. This may also reflect that in the DT model of this study, SI was suitable for determining the risk of pancreatic injury according to level of lipase but not that of amylase.

In some medical centers, normal serum levels of amylase and lipase are set at $95 \mathrm{U} / \mathrm{L}$ and $38 \mathrm{U} / \mathrm{L}$, respectively [21]. In the present study, serum levels $>137 \mathrm{U} / \mathrm{L}$ and $>51 \mathrm{U} / \mathrm{L}$ for amylase and lipase, respectively, were set as abnormal levels according to hospital guidelines for the Taiwanese population. The definition of high amylase and lipase levels may vary among different studies and medical institutions. In a prospective study, Mahajan et al. reported that using cutoffs of $250 \mathrm{U} / \mathrm{L}$ and $100 \mathrm{U} / \mathrm{L}$ for serum amylase and lipase levels, respectively, a combined serum amylase and lipase assessment showed $100 \%$ specificity and $85 \%$ sensitivity for predicting pancreatic injury in patients with blunt abdominal trauma [12]. In addition, Nadler et al. suggested that values of serum amylase $>200 \mathrm{U} / \mathrm{L}$ and lipase $>1800 \mathrm{U} / \mathrm{L}$ were useful cutoffs for detecting patients who were more likely to have major pancreatic duct injuries [47]. Obviously, the choice of cutoff value for amylase or lipase as an abnormal expression would have a remarkable impact on diagnostic accuracy. One advantage of the DT algorithm is its construction does not require any domain knowledge or parameter setting, thus making it appropriate for exploratory knowledge discovery. Unlike conventional statistical analyses that tend to identify the different variables among the compared groups, the DT algorithm uses a procedure for classifying data based on their attributes of the evaluated outcome. The nodes and their cutoff values were automatically identified as important determinative variables in the prediction of pancreatic injury. For example, despite a significantly younger age, higher lipase level, lower glucose level, and higher percentage of neutrophils among patients with pancreatic injury than those without, in this study there was even no significant difference in SI between patients with and without pancreatic injury.

Further, among patients with lipase level $<154 \mathrm{U} / \mathrm{L}$, an AIS score indicating abdominal injury is also important in determining the risk of pancreatic injury. No pancreatic injury was found in patients with lipase level $<154 \mathrm{U} / \mathrm{L}$ and without an elevated AIS score for the abdomen. If there was associated injury to the abdomen indicated by the AIS score, then the levels of glucose and amylase and the neutrophil percentage provided additional information for determining the risk of pancreatic injury. According to this DT model, it is impossible to determine the occurrence of pancreatic injury with very high confidence among patients with elevated pancreatic enzymes in the serum. Anyhow, considering that few data are available for identifying these high-risk individuals to guide physicians in determining which patients will likely need further investigation, this model is easy and cost effective and may be helpful in identifying patients with a high risk of pancreatic injury. Nevertheless, the above limitation indicates that there is room for improvement in the established DT model.

Because the higher rate of patients without pancreatic injury than those with pancreatic injury would be accompanied by a high accuracy and specificity in the prediction of the illness, in that event, we would rather focus on the sensitivity between DT and multivariate LR models. In this study, the DT model had a higher sensitivity than LR in the training set $(91.4 \%$ vs. $56.8 \%$, respectively) and a comparable sensitivity than LR in the test set $(72.7 \%$ vs. $77.7 \%$, respectively). Nontheless, the present study has some additional limitations. The first of these is the selection bias associated with the retrospective study design. In such circumstance, an overfit in analyzing the collected data may be encountered and the relative small sample size would limit the value of validating the model. A prospective cohort study would get more valuable information to test the established DT model. Second, the diagnosis value of the presence of pancreatic enzymes, especially amylase level, is time dependent. Some authors have proposed that serum and lipase levels measured within $3 \mathrm{~h}$ after trauma have no diagnostic value [12]. Although amylase and lipase levels were checked after consultation with a general surgeon for most of our patients, measurements were performed within $3 \mathrm{~h}$ after trauma in some patients, which may have caused a selection bias. Third, it has been reported that higher 
grade injuries to the pancreas tend to result in significantly elevated mean levels of serum amylase and lipase than lower grade injuries [12]. The degree of injury to the pancreas parenchyma was not investigated in this study; thus the value of the information provided is limited. Fourth, amylase and lipase are not routinely measured in the emergency department, only for suspicion of a pancreatic injury or under the recommendation of a general surgeon; therefore, the inclusion of patients with elevated pancreatic enzymes but not those with abdominal injury in the study population may result in selection bias. Further, future studies may consider the possibility of incorporating a patient into the model which considers the patient as the most important member of the health team [48]. Finally, the study was limited to a single center; patient injury characteristics may vary from those observed at other institutions, thereby limiting the generalizability of the findings. The work carried out in multiple centers may provide more valuable information to the establishment of the DT model.

\section{Conclusions}

We established a DT model using lipase level, SI, and additional conditions (elevated AIS score indicating abdominal injury, glucose level $<158 \mathrm{mg} / \mathrm{dL}$, amylase level $<90 \mathrm{U} / \mathrm{L}$, and neutrophils $\geq 76 \%$ ) as important nodes to predict three groups of patients with a high risk of pancreatic injury. The proposed decision-making algorithm may help to identify a pancreatic injury in trauma patients with elevated serum amylase or lipase levels.

Acknowledgments: We appreciate help with the statistical analysis extended by the Biostatistics Center, Kaohsiung Chang Gung Memorial Hospital. This research was supported by a grant from CMRPG8F1861.

Author Contributions: Cheng-Shyuan Rau wrote the manuscript, Shao-Chun Wu was involved in the literature review, Peng-Chen Chien established and tested the decision tree model, Pao-Jen Kuo was responsible for the integrity of the registered data, Yi-Chun Chen performed the statistical analyses, Hsiao-Yun Hsieh proofread the manuscript, Ching-Hua Hsieh designed the study and contributed to the data analysis, and Hang-Tsung Liu helped to interpret the results of the decision tree model. All authors read and approved the final manuscript.

Conflicts of Interest: The authors declare no conflict of interest.

\section{References}

1. Jurkovich, G.J.; Carrico, C.J. Pancreatic trauma. Surg. Clin. N. Am. 1990, 70, 575-593. [CrossRef]

2. Wisner, D.H.; Wold, R.L.; Frey, C.F. Diagnosis and treatment of pancreatic injuries. An analysis of management principles. Arch. Surg. 1990, 125, 1109-1113. [CrossRef] [PubMed]

3. Patton, J.H., Jr.; Lyden, S.P.; Croce, M.A.; Pritchard, F.E.; Minard, G.; Kudsk, K.A.; Fabian, T.C. Pancreatic trauma: A simplified management guideline. J. Trauma 1997, 43, 234-239, discussion 239-241. [CrossRef] [PubMed]

4. $\quad$ Lin, B.C.; Chen, R.J.; Fang, J.F.; Hsu, Y.P.; Kao, Y.C.; Kao, J.L. Management of blunt major pancreatic injury. J. Trauma 2004, 56, 774-778. [CrossRef] [PubMed]

5. Smego, D.R.; Richardson, J.D.; Flint, L.M. Determinants of outcome in pancreatic trauma. J. Trauma 1985, 25, 771-776. [CrossRef] [PubMed]

6. Cirillo, R.L., Jr.; Koniaris, L.G. Detecting blunt pancreatic injuries. J. Gastrointest. Surg. 2002, 6, 587-598. [CrossRef]

7. Stawicki, S.P.; Schwab, C.W. Pancreatic trauma: Demographics, diagnosis, and management. Am. Surg. 2008, 74, 1133-1145. [PubMed]

8. Tietz, N.W. Support of the diagnosis of pancreatitis by enzyme tests-Old problems, new techniques. Clin. Chim. Acta 1997, 257, 85-98. [CrossRef]

9. Schmid-Schonbein, G.W.; Hugli, T.E. A new hypothesis for microvascular inflammation in shock and multiorgan failure: Self-digestion by pancreatic enzymes. Microcirculation 2005, 12, 71-82. [CrossRef] [PubMed]

10. Pieper-Bigelow, C.; Strocchi, A.; Levitt, M.D. Where does serum amylase come from and where does it go? Gastroenterol. Clin. N. Am. 1990, 19, 793-810.

11. Gumaste, V.V.; Roditis, N.; Mehta, D.; Dave, P.B. Serum lipase levels in nonpancreatic abdominal pain versus acute pancreatitis. Am. J. Gastroenterol. 1993, 88, 2051-2055. [PubMed] 
12. Mahajan, A.; Kadavigere, R.; Sripathi, S.; Rodrigues, G.S.; Rao, V.R.; Koteshwar, P. Utility of serum pancreatic enzyme levels in diagnosing blunt trauma to the pancreas: A prospective study with systematic review. Injury 2014, 45, 1384-1393. [CrossRef] [PubMed]

13. Boulanger, B.R.; Milzman, D.P.; Rosati, C.; Rodriguez, A. The clinical significance of acute hyperamylasemia after blunt trauma. Can. J. Surg. 1993, 36, 63-69. [PubMed]

14. Buechter, K.J.; Arnold, M.; Steele, B.; Martin, L.; Byers, P.; Gomez, G.; Zeppa, R.; Augenstein, J. The use of serum amylase and lipase in evaluating and managing blunt abdominal trauma. Am. Surg. 1990, 56, $204-208$. [PubMed]

15. Keller, M.S.; Coln, C.E.; Trimble, J.A.; Green, M.C.; Weber, T.R. The utility of routine trauma laboratories in pediatric trauma resuscitations. Am. J. Surg. 2004, 188, 671-678. [CrossRef] [PubMed]

16. Moretz, J.A., 3rd; Campbell, D.P.; Parker, D.E.; Williams, G.R. Significance of serum amylase level in evaluating pancreatic trauma. Am. J. Surg. 1975, 130, 739-741. [CrossRef]

17. Frank, B.; Gottlieb, K. Amylase normal, lipase elevated: Is it pancreatitis? A case series and review of the literature. Am. J. Gastroenterol. 1999, 94, 463-469. [PubMed]

18. Skude, G.; Rothman, U. Amylase isoenzymes in serum after maxillo-facial surgery. Scand. J. Plast. Reconstr. Surg. 1973, 7, 105-109. [CrossRef] [PubMed]

19. Sakorafas, G.H.; Tsiotos, G.G.; Sarr, M.G. Ischemia/Reperfusion-Induced pancreatitis. Dig. Surg. 2000, 17, 3-14. [CrossRef] [PubMed]

20. Malinoski, D.J.; Hadjizacharia, P.; Salim, A.; Kim, H.; Dolich, M.O.; Cinat, M.; Barrios, C.; Lekawa, M.E.; Hoyt, D.B. Elevated serum pancreatic enzyme levels after hemorrhagic shock predict organ failure and death. J. Trauma 2009, 67, 445-449. [CrossRef] [PubMed]

21. Kumar, S.; Sagar, S.; Subramanian, A.; Albert, V.; Pandey, R.M.; Kapoor, N. Evaluation of amylase and lipase levels in blunt trauma abdomen patients. J. Emerg. Trauma Shock 2012, 5, 135-142. [PubMed]

22. Liu, K.J.; Atten, M.J.; Lichtor, T.; Cho, M.J.; Hawkins, D.; Panizales, E.; Busker, J.; Stone, J.; Donahue, P.E. Serum amylase and lipase elevation is associated with intracranial events. Am. Surg. 2001, 67, 215-219, discussion 219-220. [PubMed]

23. Bouwman, D.L.; Altshuler, J.; Weaver, D.W. Hyperamylasemia: A result of intracranial bleeding. Surgery 1983, 94, 318-323. [PubMed]

24. Chen, C.C. Clinical implication of increased pancreatic enzymes in ICU patients. J. Chin. Med. Assoc. 2010, 73, 129-130. [CrossRef]

25. Lee, C.C.; Chung, W.Y.; Shih, Y.H. Elevated amylase and lipase levels in the neurosurgery intensive care unit. J. Chin. Med. Assoc. 2010, 73, 8-14. [CrossRef]

26. Pezzilli, R.; Morselli-Labate, A.M.; Romboli, E.; Dibenedetti, F.; Massa, M.; Migliori, M.; Barakat, B.; Merlini, G.; Corinaldesi, R.; Melzi d'Eril, G.V. Pancreatic involvement during the early phase of shock. JOP J. Pancreas 2002, 3, 139-143.

27. Farion, K.; Michalowski, W.; Wilk, S.; O'Sullivan, D.; Matwin, S. A tree-based decision model to support prediction of the severity of asthma exacerbations in children. J. Med. Syst. 2010, 34, 551-562. [CrossRef] [PubMed]

28. Zintzaras, E.; Bai, M.; Douligeris, C.; Kowald, A.; Kanavaros, P. A tree-based decision rule for identifying profile groups of cases without predefined classes: Application in diffuse large B-cell lymphomas. Comput. Biol. Med. 2007, 37, 637-641. [CrossRef] [PubMed]

29. Kasbekar, P.U.; Goel, P.; Jadhav, S.P. A Decision Tree Analysis of Diabetic Foot Amputation Risk in Indian Patients. Front. Endocrinol. 2017, 8, 25. [CrossRef] [PubMed]

30. Hsieh, C.H.; Hsu, S.Y.; Hsieh, H.Y.; Chen, Y.C. Differences between the sexes in motorcycle-related injuries and fatalities at a Taiwanese level I trauma center. Biomed. J. 2017, 40, 113-120. [CrossRef] [PubMed]

31. Hsieh, C.H.; Liu, H.T.; Hsu, S.Y.; Hsieh, H.Y.; Chen, Y.C. Motorcycle-related hospitalizations of the elderly. Biomed. J. 2017, 40, 121-128. [CrossRef] [PubMed]

32. Chang, L.Y.; Wang, H.W. Analysis of traffic injury severity: An application of non-parametric classification tree techniques. Accid. Anal. Prev. 2006, 38, 1019-1027. [CrossRef] [PubMed]

33. Ripley, B. Tree: Classification and Regression Trees. R Package Version 1.0-34. 2013. Available online: http:/ /CRAN.R-project.org/package=tree (accessed on 14 November 2017). 
34. Guilbault, R.W.R.; Ohlsson, M.A.; Afonso, A.M.; Ebell, M.H. External Validation of Two Classification and Regression Tree Models to Predict the Outcome of Inpatient Cardiopulmonary Resuscitation. J. Viral Hepat. 2017, 32, 333-338. [CrossRef] [PubMed]

35. Shi, K.Q.; Zhou, Y.Y.; Yan, H.D.; Li, H.; Wu, F.L.; Xie, Y.Y.; Braddock, M.; Lin, X.Y.; Zheng, M.H. Classification and regression tree analysis of acute-on-chronic hepatitis B liver failure: Seeing the forest for the trees. J. Viral Hepat. 2017, 24, 132-140. [CrossRef] [PubMed]

36. Zimmerman, R.K.; Balasubramani, G.K.; Nowalk, M.P.; Eng, H.; Urbanski, L.; Jackson, M.L.; Jackson, L.A.; McLean, H.Q.; Belongia, E.A.; Monto, A.S.; et al. Classification and Regression Tree (CART) analysis to predict influenza in primary care patients. BMC Infect. Dis. 2016, 16, 503. [CrossRef] [PubMed]

37. Takahashi, M.; Maemura, K.; Sawada, Y.; Yoshioka, T.; Sugimoto, T. Hyperamylasemia in critically injured patients. J. Trauma 1980, 20, 951-955. [CrossRef] [PubMed]

38. Matsuno, W.C.; Huang, C.J.; Garcia, N.M.; Roy, L.C.; Davis, J. Amylase and lipase measurements in paediatric patients with traumatic pancreatic injuries. Injury 2009, 40, 66-71. [CrossRef] [PubMed]

39. Allgower, M.; Burri, C. [“Shock index"]. Dtsch. Med. Wochenschr. 1967, 92, 1947-1950. [PubMed]

40. Mitra, B.; Fitzgerald, M.; Chan, J. The utility of a shock index $>/=1$ as an indication for pre-hospital oxygen carrier administration in major trauma. Injury 2014, 45, 61-65. [CrossRef] [PubMed]

41. DeMuro, J.P.; Simmons, S.; Jax, J.; Gianelli, S.M. Application of the Shock Index to the prediction of need for hemostasis intervention. Am. J. Emerg. Med. 2013, 31, 1260-1263. [CrossRef] [PubMed]

42. Rau, C.S.; Wu, S.C.; Kuo, S.C.; Pao-Jen, K.; Shiun-Yuan, H.; Chen, Y.C.; Hsieh, H.Y.; Hsieh, C.H.; Liu, H.T. Prediction of Massive Transfusion in Trauma Patients with Shock Index, Modified Shock Index, and Age Shock Index. Int. J. Environ. Res. Public Health 2016, 13, 683. [CrossRef] [PubMed]

43. Mutschler, M.; Nienaber, U.; Munzberg, M.; Wolfl, C.; Schoechl, H.; Paffrath, T.; Bouillon, B.; Maegele, M. The Shock Index revisited-A fast guide to transfusion requirement? A retrospective analysis on 21,853 patients derived from the TraumaRegister DGU. Crit. Care 2013, 17, R172. [CrossRef] [PubMed]

44. Birkhahn, R.H.; Gaeta, T.J.; Terry, D.; Bove, J.J.; Tloczkowski, J. Shock index in diagnosing early acute hypovolemia. Am. J. Emerg. Med. 2005, 23, 323-326. [CrossRef] [PubMed]

45. Rassameehiran, S.; Teerakanok, J.; Suchartlikitwong, S.; Nugent, K. Utility of the Shock Index for Risk Stratification in Patients with Acute Upper Gastrointestinal Bleeding. South. Med. J. 2017, 110, 738-743. [CrossRef] [PubMed]

46. Vandromme, M.J.; Griffin, R.L.; Kerby, J.D.; McGwin, G., Jr.; Rue, L.W., 3rd; Weinberg, J.A. Identifying risk for massive transfusion in the relatively normotensive patient: Utility of the prehospital shock index. J. Trauma 2011, 70, 384-388, discussion 388-390. [CrossRef] [PubMed]

47. Nadler, E.P.; Gardner, M.; Schall, L.C.; Lynch, J.M.; Ford, H.R. Management of blunt pancreatic injury in children. J. Trauma 1999, 47, 1098-1103. [CrossRef] [PubMed]

48. Ciccone, M.M.; Aquilino, A.; Cortese, F.; Scicchitano, P.; Sassara, M.; Mola, E.; Rollo, R.; Caldarola, P.; Giorgino, F.; Pomo, V.; et al. Feasibility and effectiveness of a disease and care management model in the primary health care system for patients with heart failure and diabetes (Project Leonardo). Vascular Health Risk Manag. 2010, 6, 297-305. [CrossRef]

(C) 2018 by the authors. Licensee MDPI, Basel, Switzerland. This article is an open access article distributed under the terms and conditions of the Creative Commons Attribution (CC BY) license (http://creativecommons.org/licenses/by/4.0/). 